\title{
Retraction Note to: Research on coastline climate environment and student psychology in coastal cities based on artificial intelligence
}

\author{
Haihong $\mathrm{Li}^{1}$ · Guangtao Zhang ${ }^{2}$
}

Published online: 9 November 2021

(c) Saudi Society for Geosciences 2021

Retraction Note to: Arabian Journal of Geosciences (2021) 14: 1035 https://doi.org/10.1007/s12517-021-07255-4

The Editor-in-Chief and the Publisher have retracted this article because the content of this article is nonsensical. The peer review process was not carried out in accordance with the Publisher's peer review policy. Author Haihong Li has not responded to correspondence regarding this retraction. The publisher has not been able to obtain a current email address for author Guangtao Zhang.

The original article can be found online at https://doi.org/10.1007/ s12517-021-07255-4.

Haihong Li

lhhongxinli@126.com

1 School of Marxism, Shandong Technology and Business University, Yantai 264005, Shandong, China

2 Department of Architecture and Civil Engineering, Yantai Vocational College, Yantai 264670, Shandong, China 